\title{
Article \\ Optimal Planning for Energy Stations and Networks in Distributed Energy Systems Based on Voronoi Diagram and Load Characteristics
}

\author{
Jiazheng Wu, Jiamin Yuan, Yingjun Ruan *, Fanyue Qian (1) and Hua Meng \\ College of Mechanical and Energy Engineering, Tongji University, Shanghai 201804, China; \\ tjwujz@tongji.edu.cn (J.W.); yjm_9703@163.com (J.Y.); qianfanyue91@163.com (F.Q.); mengh@tongji.edu.cn (H.M.) \\ * Correspondence: ruanyj@tongji.edu.cn
}

check for updates

Citation: Wu, J.; Yuan, J.; Ruan, Y.; Qian, F.; Meng, H. Optimal Planning for Energy Stations and Networks in Distributed Energy Systems Based on Voronoi Diagram and Load Characteristics. Appl. Sci. 2021, 11, 7526. https://doi.org/10.3390/ app11167526

Academic Editor:

Amjad Anvari-Moghaddam

Received: 17 July 2021

Accepted: 12 August 2021

Published: 17 August 2021

Publisher's Note: MDPI stays neutral with regard to jurisdictional claims in published maps and institutional affiliations.

Copyright: (c) 2021 by the authors. Licensee MDPI, Basel, Switzerland. This article is an open access article distributed under the terms and conditions of the Creative Commons Attribution (CC BY) license (https:// creativecommons.org/licenses/by/ $4.0 /)$.

\begin{abstract}
In the existing station network planning of distributed energy systems (DESs), most of them determined the location of energy station in the alternative station site, there was a lack of a mature energy station location optimization method, and the factor load was not considered in the division of energy supply scope. This paper aimed to propose an optimal site approach for distributed energy stations based on Voronoi diagram, in which all possible candidates of energy station locations were considered. The candidate sites could be any point in the whole area. Simultaneously, after analyzing the limitations of the traditional energy supply partition method, we proposed a new energy supply partition optimization method, relative-load-distance. It was found that the annual cost of the whole system was significantly reduced by $1 \%$, although the cost of the network in the optimized supply area was increased, compared with the supply area obtained by the partition method based on the principle of minimum distance. In addition, by adjusting the coefficient $\mathrm{K}$ in the relative-load-distance, the effectiveness of the optimization method in DES planning was verified.
\end{abstract}

Keywords: distributed energy system; energy station site selection; Voronoi diagram; energy supply area optimization; relative-load-distance

\section{Introduction \\ 1.1. Background and Motivation}

In recent years, with the advancement of urbanization, the rapid climate change caused by fossil fuel consumption has become increasingly prominent. There is an urgent need to deal with the challenges brought up by climate change, as its consequences have seriously affected our society, with projections of even worse consequences in the near future [1]. For these reasons, governments and organizations around the world have accelerated the deep adjustment of the energy pattern and turned to a more sustainable development model to meet the large-scale global energy demand.

A possible solution to improve sustainability is to develop high-efficiency energy systems with a high penetration of renewable energy resources, which are abundant and are clean substitutes to traditional fuels. However, renewable energy has the disadvantages of intermittency and volatility, which will lead to complex prediction methods and energy management strategies [2]. To overcome these challenges, distributed energy systems (DESs) have been proposed.

DESs for supplying electricity, heating, or cooling have been widely employed for industrial and residential applications in many countries [3], with high energy utilization efficiency [4]. Different from the traditional energy system, DES involves on-site production and consumption. Therefore, a DES can make full use of local resources and be customized according to the users' features, which can obtain better economic and environmental benefits. In addition, DESs can be used to exploit waste energy to improve the efficiency of the system, so as to minimize carbon dioxide emissions. DESs can further be used 
to deal with climate change. However, although DESs possess many advantages, the design of a DES is not a simple task, which has become the bottleneck restricting the development of DESs. Owing to the great differences among users in the region [5], a DES needs to comprehensively consider all energy supply processes, mainly including source, transmission, and consumption. However, few designs have fully considered the above factors and most lack integrity and a systematic nature, resulting in poor system efficiency and economic benefits. Therefore, it is very necessary to realize the collaborative planning of energy stations and networks of DES, which can save investment and improve the economy of DES to the greatest extent.

\subsection{Literature Review}

The planning and design of DES has been widely studied because of its complex structure, including energy stations, transmission networks, and buildings [6]. The planning and design of DES is divided into two parts: energy station location and transmission network optimization.

At present, many studies have been carried out on the optimization of the pipe network layout of DES. The network connects energy stations and consumers, and its performance is affected by factors such as location, material, diameter [7], thermal insulation, and heat loss [8]. Zeng et al. [9] established the cost model of the energy pipe network, considering the influence of the change in cooling and heating load on the operation cost of the pipe network, and taking the minimum cost of pipe network construction as the objective. The genetic algorithm was used to solve the problem of pipe diameter optimization. By combining the genetic algorithm (GA) with local search technology, Chan et al. [10] proposed an algorithm to find the optimal layout and pipe diameter of a regional cooling network in a given candidate location. To minimize the total life cycle cost, Chen et al. [11] proposed a Prim algorithm with a dynamic flow weight set to solve the cost problem, and optimized the pipe network layout based on dynamic minimum spanning tree and optimal path. Mosbah et al. [12] used the minimum spanning tree to determine the layout of the transmission network. Dobersek et al. [13] focused on transforming the PNs' layout into the flow distribution in the pipeline route for selection, in which a PN's layout method was proposed based on the nonlinear programming model. The studies mentioned above in the literature usually constructed linear models to optimize low span networks, but their adaptability was often limited for nonlinear factors. In addition, the shortest path method was a common path search method, such as Astar search algorithm [14] and Dijkstra algorithm [15]. The shortest path algorithm cannot consider the coupling relationship between users. Therefore, it was difficult to obtain the optimal solution.

In the actual design, the optimal station is coupled with the network topology, so the location of the energy station must be optimized before the pipe network is optimized. However, there is still little research on the collaborative planning of energy stations and pipe networks. Chen [16] put forward the concept of "energy distance". Taking the minimum energy distance as the objective function, combined with graph theory, the station-network layout optimization model of a regional energy system is established. However, this method must exhaust all alternative energy station combinations. Yan et al. [14] determined the location of an energy station and energy storage station by kernel density estimation, and the shortest path method was used to optimize the layout of the pipe network. Wang et al. [17] selected the DES site in a specific region through multi-objective analysis. Wang et al. [18] employed the minimum spanning tree to obtain the DES site. Xu et al. [19] put forward a decentralized optimization and comprehensive decision-making planning strategy, and used the number of energy stations to be built, the coverage rate, and the transmission load capacity of pipeline network as three objective functions. In addition, a heuristic random search method was used to determine the location of the energy station with the minimum transmission loss [20]. However, the above studies determined the sites in the candidate sites; this is not applicable when it is difficult to determine the site of the 
station to be selected in advance. Further, energy networks were not arranged along the road network.

\subsection{Contribution and Paper Organization}

Previous studies have proposed various methods to optimize the energy station and network of DESs, which have been verified from the perspective of economy. However, the site selection of an energy station mainly depends on the given set of alternative station sites, which is difficult to apply in the scenario where it is difficult to determine the station site in advance. In addition, the energy supply range division of energy stations proposed in the existing literature is based on the principle of minimum distance, without considering the factor of load, which may lead to a large investment scale of the energy system. Therefore, combined with the characteristics of Voronoi diagram, this paper proposes a new criterion for range division, which contributes to the aforementioned shortfalls. The contributions of this study are as follows:

(1) A method combining Voronoi diagram and minimum spanning tree is proposed to determine the location of energy stations and optimize the layout of the pipe network.

(2) Based on the influence of load value on the construction cost of energy station, an optimization evaluation index of energy supply range considering load value is constructed.

(3) Three problems in DES optimization are comprehensively considered and solved: (a) the location of energy stations in the region; (b) the ownership between energy stations and energy consumers; and (c) the layout of the transmission network.

The remainder of this paper is organized as follows. In Section 2, the DES station network planning model is formulated. In Section 3, the objective function of station network planning is introduced, and the optimal method of energy supply area based on relative-load-distance is proposed. In Section 4, the case study is carried out through two parts: (a) The comparison between the traditional model and the model based on relative-load-distance and (b) the influence of coefficient $\mathrm{K}$ on the economy of energy system. Section 5 concludes this paper.

\section{Methodology}

2.1. The Definition of the Voronoi Diagram and the Characteristic of Maximum Empty Circle

On the plane, a Voronoi diagram is a graph formed by taking the vertices of point set $R$ as growth elements, and then these growth elements expand outward at the same speed until they meet, as shown in Figure 1.

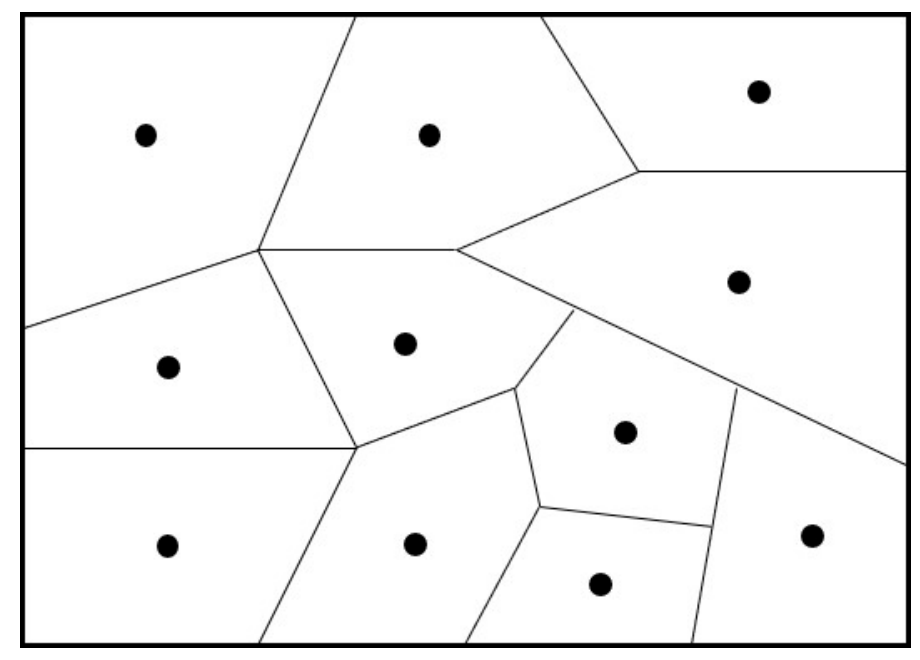

Figure 1. Conventional Voronoi diagram. 
Suppose that $R=\left\{R_{1}, R_{2}, \ldots, R_{n}\right\}, 3 \leq n \leq \infty$ is the set of control points in the plane, and these points are different from each other, then the Voronoi diagram of arbitrary point is defined as

$$
V\left(R_{i}\right)=\left\{x \in V\left(R_{i}\right) \mid d\left(x, R_{i}\right) \leq d\left(x, R_{j}\right), j=1,2, \cdots, n ; j \neq i\right\}
$$

In the formula, $x$ is any point in the plane and $d\left(x, R_{i}\right)$ represents the distance between $x$ and $R_{i}, R_{i} \neq R_{j}, i \neq j, i, j \in\{1,2, \cdots, n\} . V\left(R_{i}\right)$ represents the V-polygon of vertex $R_{i}$ and the Voronoi diagram is formed by the V-polygon.

There are many mathematical characteristics of the Voronoi diagram, such as the characteristics of hollow circle and effective range, which can be used in the location of public facilities. The characteristic of hollow circle means that, in the Voronoi diagram, each node is at least the intersection of three v-polygons. If a circle $\mathrm{P}_{i}$ is made with the node $Q_{i}$ as the center of the circle, and the circle $P_{i}$ passes through all the corresponding vertices of the polygon connected by node $Q_{i}$, then any other vertex in the Voronoi diagram will not fall in the circle $P_{i}$. The circle $P_{i}$ is also called the hollow circle, and the circle with the largest radius that can be connected by the corresponding node $Q_{i}$ is called the largest hollow circle, as shown in Figure 2.

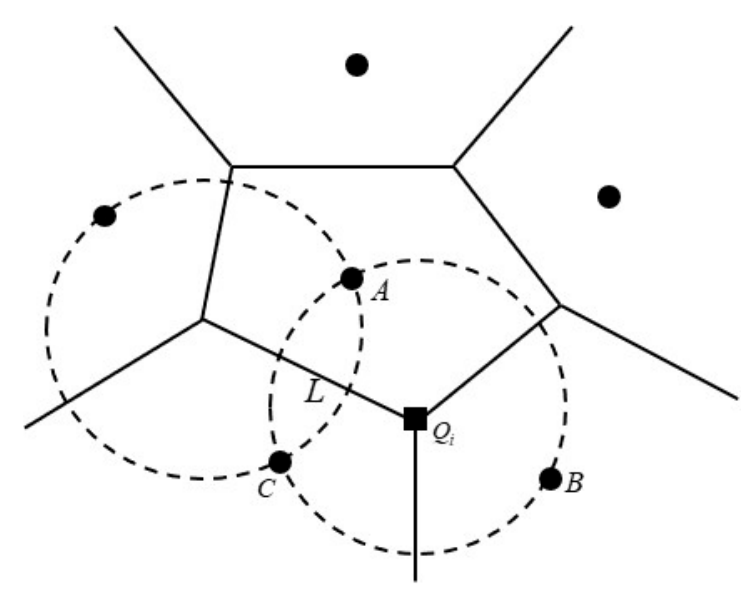

Figure 2. The characteristic of hollow circle in a Voronoi diagram.

We can draw a conclusion from the above definitions and figures that the distance from a point on line $\mathrm{L}$ to $\mathrm{A}$ and $\mathrm{C}$ is equal.

\subsection{Determination of New Energy Station Initial Site and Division of Energy Supply Area}

According to the selection of the initial sites of the energy stations, the problem is solved using the definition of the Voronoi diagram and the characteristic of maximum hollow circle in Section 2.1. The location of the node $Q_{i}$ may become the site of the new energy station, that is, the position shown by the center of the circle in the figure. Because the hollow circle is the largest local blank area, its center is the growth point of the new energy station. In this paper, the method of selecting the initial site is shown as follows.

The center of the planning area is taken as the center of the initial station, and the half distance from the boundary of the area to the center is taken as the radius to make a circle. The ellipse $\mathrm{N}$ is divided equally, and each dividing point is the initial station. When the number of energy stations exceeds five, make two circles with the radius of one-third and two-thirds of the distance from the regional boundary to the center, divide the ellipse $\mathrm{N}$ equally, and each dividing point is the initial site, as shown in Figure 3. 


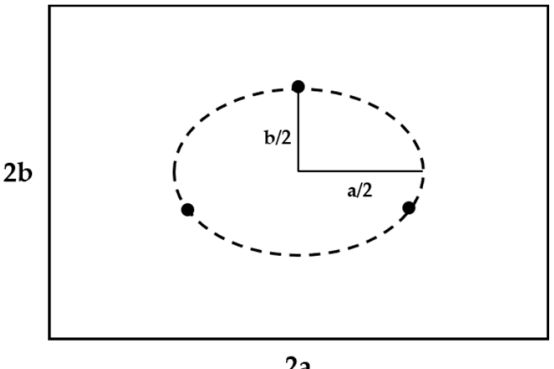

(a) $2 \leq N \leq 5$

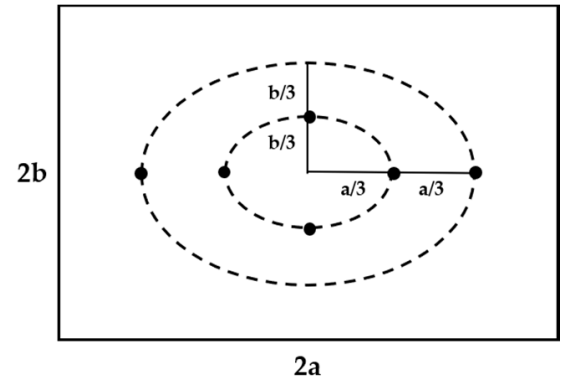

(b) $N \geq 6$

Figure 3. Initial site selection.

Generally, after the initial energy station sites are determined, we need to divide the whole area into several sub supply areas to reduce the transmission loss. According to the formula, the division method of energy supply area is as follows. Suppose that a planning area will be divided into $\mathrm{N}$ sub-regions, each sub-region will be set with an energy station, $\mathrm{M}$ load points in the area will be served by the $\mathrm{N}$ energy stations, and each load point will be powered by the nearest energy station, then the expression of energy supply range division is as follows:

$$
V\left(R_{i}\right)=\left\{p \mid d\left(m, R_{i}\right) \leq d\left(m, R_{j}\right), j=1,2, \ldots, n ; j \neq i\right\}
$$

In the formula, $R=\left\{R_{1}, R_{2}, \ldots, R_{n}\right\}$ is a collection of energy stations, $R_{i} \neq R_{j}, i \neq j$, $i, j \in\{1,2, \ldots, n\} . m$ represents any load point in a plane. $d\left(m, R_{i}\right)$ is the Euclidean distance between point $\mathrm{m}$ and $R_{i}$.

\subsection{Energy Station Site Optimization Based on an Improved P-Median Model}

The location of the energy station is not only related to the distance from the load point, but also to the load of users in the region. Users with larger load require a shorter distance to the energy stations to minimize energy loss and investments. However, the initial station locations based on the hollow circle characteristic of the Voronoi diagram in Section 2.2 may not be located in the load distribution centers, so this section will establish an improved P-median model to optimize the station locations.

The P-median problem is to study how to locate and set up P service points, so that the average weighting distance from all demand points to service points is the shortest. The energy station location problem can be simply described as follows: give an undirected network graph $G(V, E)$, then find a subset $V_{p}$ from the road node collection $V$, so that the sum of the distances from the road node collection $\left\{V-V_{p}\right\}$ to the nearest vertex in $V_{p}$ is the minimum.

The traditional P-median model takes the linear distance between the load point and the energy station as the shortest energy supply distance [21]. However, in order to make full use of resources and reduce the construction cost of energy supply pipelines, the energy supply routes in practice are usually laid along the road edge [18]. Therefore, this paper uses an improved P-median model to select energy station locations. The model is shown as follows:

$$
\begin{aligned}
& \min Z=\sum_{m \in M} \sum_{n \in N} \alpha_{m n} d_{m n} Q_{m} \\
& d_{m n}=\left|x_{m}-x_{n}\right|+\left|y_{m}-y_{n}\right|
\end{aligned}
$$

In the formula, $\mathrm{M}$ is the collection of load points and $\mathrm{N}$ is the collection of energy stations. $Q_{m}$ is the load value of th load point $\mathrm{m} . d_{m n}$ represents the distance from the energy station $\mathrm{n}$ to the load point $\mathrm{m}$, considering that the realistic energy supply routes are generally laid along the roads. The Manhattan distance, which is closer to the actual route, is adopted, as shown in Formula (4), where $x_{m}$ and $y_{m}$ represent the spatial location 
properties of the load point $\mathrm{m}$ and $x_{n}$ and $y_{n}$ represent the spatial location properties of the energy station $\mathrm{n} . \alpha_{m n}$ represents whether the energy station $\mathrm{n}$ will serve the load point $\mathrm{m}$; if so, $\alpha_{m n}=1$, or $\alpha_{m n}=0$.

\subsection{Minimum Spanning Tree}

Network planning is based on the determination of energy station sites and the division of energy supply scope. As a general rule, the network is the basic representation of space, which can accurately represent the relationship between two connection points. Figure 4 is a graphical model of the studying area.

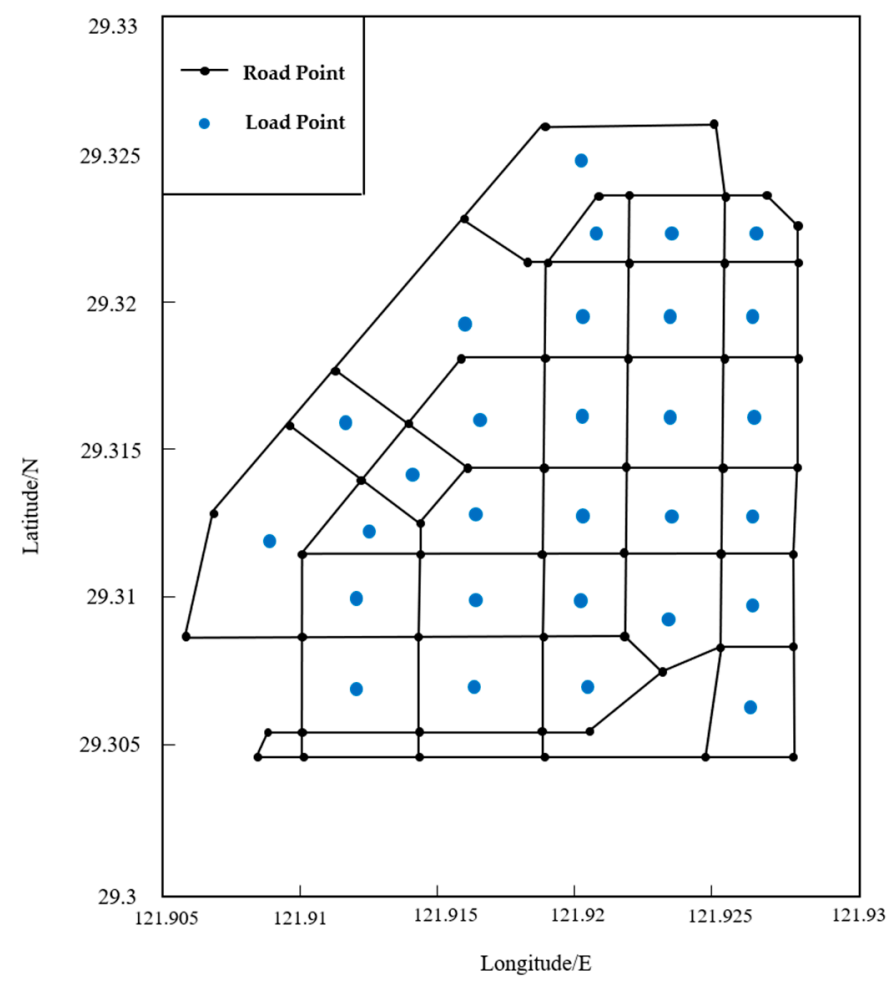

Figure 4. Graph model of the studying area.

The model can be expressed as follows:

$$
G(V, E, W)
$$

where $V$ represents a group of points, including the points of geographic coordinates of users $\left(V_{1}\right)$ represented by blue dots and road nodes $\left(V_{2}\right)$ represented by black dots. $E$ is the edge set, representing the connection between two points, and $W$ is the weight set. This is the relationship between the start point and end point on the edge.

Minimum spanning tree (MST) is often used to solve practical problems related to graph theory, and has extensive use in transportation, communication, architecture, and other fields [22]. MST requires obtaining a spanning tree, that is, to select $n-1$ edges from a weighted undirected network graph, which is still connected, and the weight of the tree should be minimized. At present, Prim algorithm [23] and Kruskal algorithm [24] are widely used in solving MST problems. In this paper, Prim algorithm is used to set up the minimum spanning tree for the layout of the energy supply network. MATLAB programming is employed to implement the process of MST. The task consists of the following steps:

Step 1: Input a weighted undirected network graph, where $V$ is the set of vertices and $E$ is the set of edges.

Step 2: Initialize $V_{\text {new }}$. 
Step 3: Select the edge $(u, v)$ with the smallest weight in the set $\mathrm{E}$, where $u$ is the element in the set $\mathrm{V}_{\text {new }}$ and $v$ is not in the set $\mathrm{V}_{\text {new }}, v \in V$.

Step 4: Add $v$ to the set $\mathrm{V}_{\text {new }}$ and add the edge $(u, v)$ to the set $\mathrm{E}_{\text {new }}$.

Step 5: Repeat Step 3 and Step 4 until $V_{\text {new }}=\mathrm{V}$.

Step 6: Output $\mathrm{V}_{\text {new }}$ and $\mathrm{E}_{\text {new }}$, which are the MST.

\section{Optimization of the Boundary of Energy Supply Area Based on Relative-Load-Distance}

In Section 2.2, the method of energy supply range division based on the Voronoi diagram is introduced. This is only a preliminary scheme, and it is necessary to optimize it to make the overall economy of the energy system the best. Generally speaking, the division of energy supply areas is to determine the attribution of load points, so the optimization of energy supply areas is to adjust the attribution of load points. However, this does not mean that all load points can be arbitrarily adjusted, such as the load points that are significantly far away from other energy stations. Therefore, this section proposes a measurement standard to determine which load points to adjust.

\subsection{Optimization Formula}

This paper takes the minimum comprehensive annual cost as the optimal scheme, that is, the sum of annual converted cost and annual maintenance cost of DES station network as the objective function. The objective function is expressed as follows:

$$
\begin{aligned}
\min C_{\text {total }} & =\min \left(C_{\text {station }}+C_{\text {pipeline }}\right) \\
& =\sum_{j=1}^{N_{s}}\left(\chi_{t}^{E S} C_{o_{j}}^{E S}+C_{m_{j}}^{E S}\right)+\sum_{i=1}^{N_{P}} \sum_{j=1}^{N_{s}}\left(\chi_{t}^{P L} C_{o_{i j}}^{P L}+C_{\Delta Q_{i j}}^{P L}+C_{\alpha_{i j}}^{P L}\right)
\end{aligned}
$$

In the formula, $C_{\text {total }}$ represents the total annual cost of energy stations and pipelines. $C_{\text {station }}$ represents the total annual cost of energy stations. $C_{\text {pipeline }}$ represents the total annual cost of pipelines. $C_{o_{j}}^{E S}$ represents the initial total investment cost of energy station $j$. $C_{m_{j}}^{E S}$ represents the annual maintenance cost of energy station $j . C_{o_{i j}}^{P L}$ represents the initial investment cost of pipe network from the energy station $j$ to the load point $i . C_{\Delta Q_{i j}}^{P L}$ represents the annual cost of heat loss. $C_{\alpha_{i j}}^{P L}$ represents the depreciation and maintenance costs from the energy station $j$ to the load point $i . \chi_{t}^{E S}$ represents standard investment effect coefficient of energy station and $\chi_{t}^{P L}$ represents standard investment effect coefficient of pipelines.

\subsubsection{Annual Conversion Cost of Initial Investment of Energy Stations}

According to [16], the expression of the initial investment cost of an energy station is

$$
C_{o}^{E S}=\left[2.188 \times\left(\frac{V^{E S} C^{E S}}{10^{7}}\right)^{0.920}+27.54\right] \times 10^{7}
$$

where $V^{E S}$ represents the total capacity of energy stations, which is determined by the maximum load of all load points in the functional area, and $C^{E S}$ represents the investment cost per unit capacity of each equipment.

\subsubsection{Annual Maintenance Cost of Energy Stations}

$$
C_{m}^{E S}=\left(\mu_{1}^{E S}+\mu_{2}^{E S}\right) \times C_{o}^{E S}
$$

In the formula, $\mu_{1}^{E S}$ represents the depreciation rate of energy stations and $\mu_{2}^{E S}$ represents the maintenance cost coefficient of energy stations. 


\subsubsection{Initial Total Investment Cost of Pipe Networks}

The annual conversion cost of initial investment in the district heating (cooling) network is shown in Formula (9).

$$
C_{o}^{P L}=\sum_{i=1}^{n} f\left(d_{i}\right) l_{i}
$$

In the formula, $n$ is the total number of pipe network segments. $d_{i}$ represents the diameter of pipe $i . f\left(d_{i}\right)$ represents the unit length cost of pipe $i . l_{i}$ represents the length of pipe $i$.

\subsubsection{Annual Cost of Heat Loss}

The cold (heat) loss of pipe network is calculated according to the principle of heat transfer, as shown in the following Equation (10):

$$
\Delta Q=\sum \frac{4 \pi \lambda l_{i}}{\ln \frac{d_{i}+2 \delta_{i}+2 \delta_{t i}}{d_{i}+2 \delta_{i}}} t_{\mathcal{C}}
$$

Converting the heat loss into electricity consumption cost is done as follows:

$$
C_{\Delta Q}^{P L}=\frac{\Delta Q}{C O P \times 10^{3}} P_{e} \times \tau
$$

In the formula, $\Delta Q$ represents the heat loss of the pipe networks. $\lambda$ represents thermal conductivity of thermal insulation materials. $t_{c}$ represents the mean temperature difference. $\delta_{i}$ represents the thickness of the pipes. $\delta_{t i}$ represents the thickness of insulation layer of pipe networks. COP is the energy efficiency ratio of DES.

\subsubsection{Annual Depreciation and Maintenance Costs of the Energy Pipe Network}

The annual depreciation and maintenance cost of the pipe network is generally calculated as a percentage of the investment of the pipe network. In the actual projects, the basic depreciation rate of the pipe network is calculated as $4.8 \%$, and the overhaul cost is calculated as $1.4 \%$. Considering the minor repair and other costs, the total depreciation rate can be calculated as $8 \sim 10 \%$. To sum up, the average annual depreciation and maintenance cost of pipe network is calculated as follows:

$$
C_{\alpha}^{P L}=\alpha \cdot C_{o}^{P L}
$$

where $\alpha$ represents the depreciation rate.

\subsection{The Criterion, Relative-Load-Distance}

We mentioned that the premise of optimizing the energy supply area of an energy station is to find out the load points that need to be adjusted, but this does not mean that any point can be adjusted. To solve this problem, this paper puts forward the criterion, "relative-load-distance", using the relative positions of the energy stations and the load points to adjust the ownership of part of the load point, and carry out the network planning, so as to obtain the most economical scheme.

First, calculate the difference between the distance from a load point to energy station 1 and the distance from the point to energy station 2 , as shown in the following equation:

$$
\Delta l=\left|\Delta l_{i-1}-\Delta l_{i-2}\right|
$$

where $\Delta l_{i-1}$ is the distance from the node $\mathrm{i}$ to energy station 1 and $\Delta l_{i-2}$ is the distance from the node $i$ to energy station 2 . 
Then, the relative-load-distance criterion of a certain point is as follows:

$$
\frac{\Delta l}{Q_{i}} \leq k \frac{R}{Q_{\text {all }}}
$$

In the formula, $Q_{i}$ represents the load value of node $i, R$ represents the energy supply radius of the planning area, $Q_{\text {all }}$ represents the total value in the area, and $k$ is the coefficient.

If the standard formula is established, it is necessary to adjust the point to another energy station; otherwise, there is no need to adjust it.

\section{Results and Discussion}

\subsection{Initial Parameters}

To validate the method proposed in Section 3, this paper analyzes a case in Ningbo, Zhejiang Province, China. The total area of the study area is 3.75 square kilometers. The area map is shown in Figure 4. The original regional map and its geographic coordinates are collected from Open Street Map and edited by JOSM. The total heating load of this area is $18.5 \mathrm{MW}$, including 29 load points. Two energy stations are planned to be built. The information of each load point is shown in Appendix A.

The simulation parameter settings are shown in the table [16]. In Table 1, the life cycle of a DES is 20 years. In the paper, the investment cost of energy station is calculated according to the load demand and the unit capacity investment cost of energy station equipment is 10,000 RMB. This paper does not study the influence of pipe diameter on the result, so the value of pipe diameter is $500 \mathrm{~mm}$. The electricity price is $0.8 \mathrm{RMB}$ per kilowatt hour, the thermal conductivity of the insulation material is $0.06 \mathrm{~W} /\left(\mathrm{m} \cdot{ }^{\circ} \mathrm{C}\right)$, and the depreciation rate is $1 \%$.

Table 1. Table of simulation parameters.

\begin{tabular}{cccccc}
\hline Parameters & Values & Units & Parameters & Values & Units \\
\hline$\chi_{t}^{E L}$ & $1 / 20$ & $1 /$ year & $\tau$ & 3360 & $\mathrm{~h}$ \\
$C^{E S}$ & 10,000 & $\mathrm{RMB} / \mathrm{kW}$ & $P_{e}$ & 0.8 & $\mathrm{RMB} /(\mathrm{kW} \cdot \mathrm{h})$ \\
$f\left(d_{500}\right)$ & 1567.21 & $\mathrm{RMB} / \mathrm{m}$ & $\lambda$ & 0.06 & $\mathrm{~W} /\left(\mathrm{m} \cdot{ }^{\circ} \mathrm{C}\right)$ \\
$\mu_{1}^{E S}$ & 0.01 & - & $t_{c}$ & 10 & ${ }^{\circ} \mathrm{C}$ \\
$\mu_{2}^{E S}$ & 0.015 & - & $\delta_{i}$ & 0.5 & $\mathrm{~m}$ \\
$\mathrm{~d}$ & 0.5 & $\mathrm{~m}$ & $\delta_{t i}$ & 0.09 & $\mathrm{~m}$ \\
$\chi_{t}^{P L}$ & $1 / 20$ & $1 /$ year & $C O P$ & 4.2 & - \\
$\alpha$ & 1 & $\%$ & & & \\
\hline
\end{tabular}

\subsection{Results}

In order to verify the performance superiority of the proposed optimization criteria, two strategies are used to plan the stations and networks. In Scheme 1, the scope of energy stations is divided according to the principle of the nearest distance. In Scheme 2, the relationship between the load points on the boundary and energy stations is considered through the relative-load-distance criterion. In this paper, the points on the boundary of the energy supply area are assigned and replaced. In Scheme 2, we assume that $k=3$.

Accordingly, the station and network planning results of Schemes 1 and 2 are represented in Figure 5 below, and Figure 6 shows the investment of each scheme. 


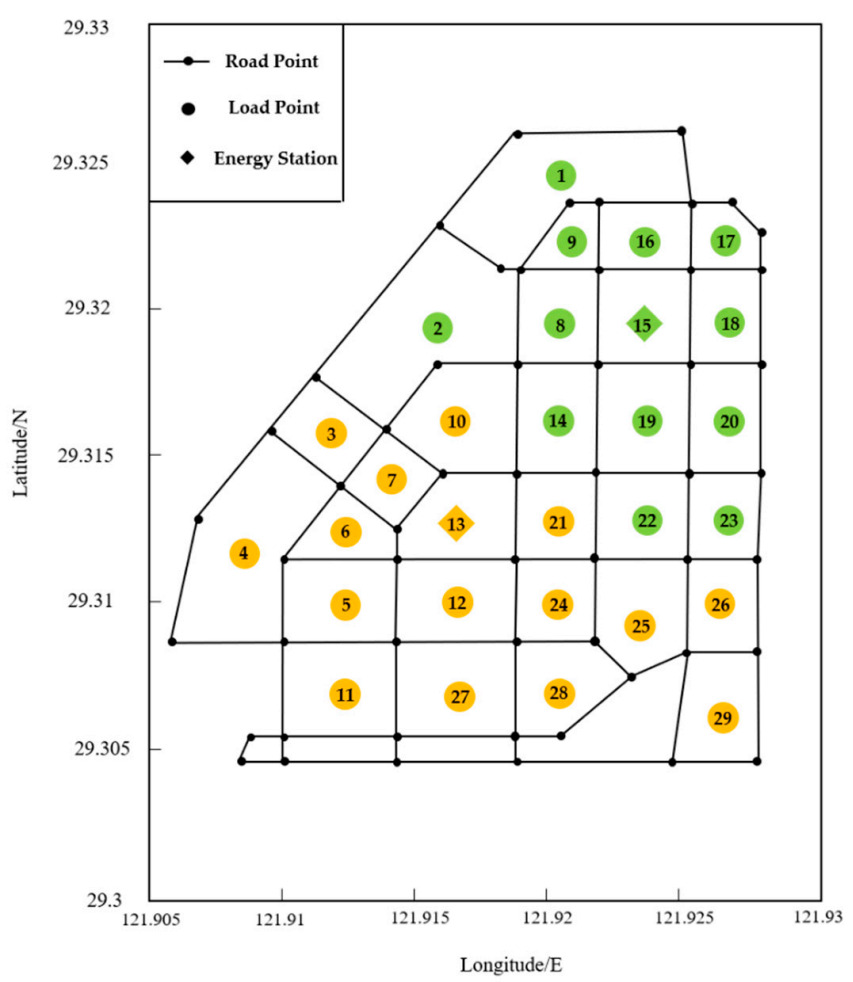

(a) Energy supply area of Scheme 1

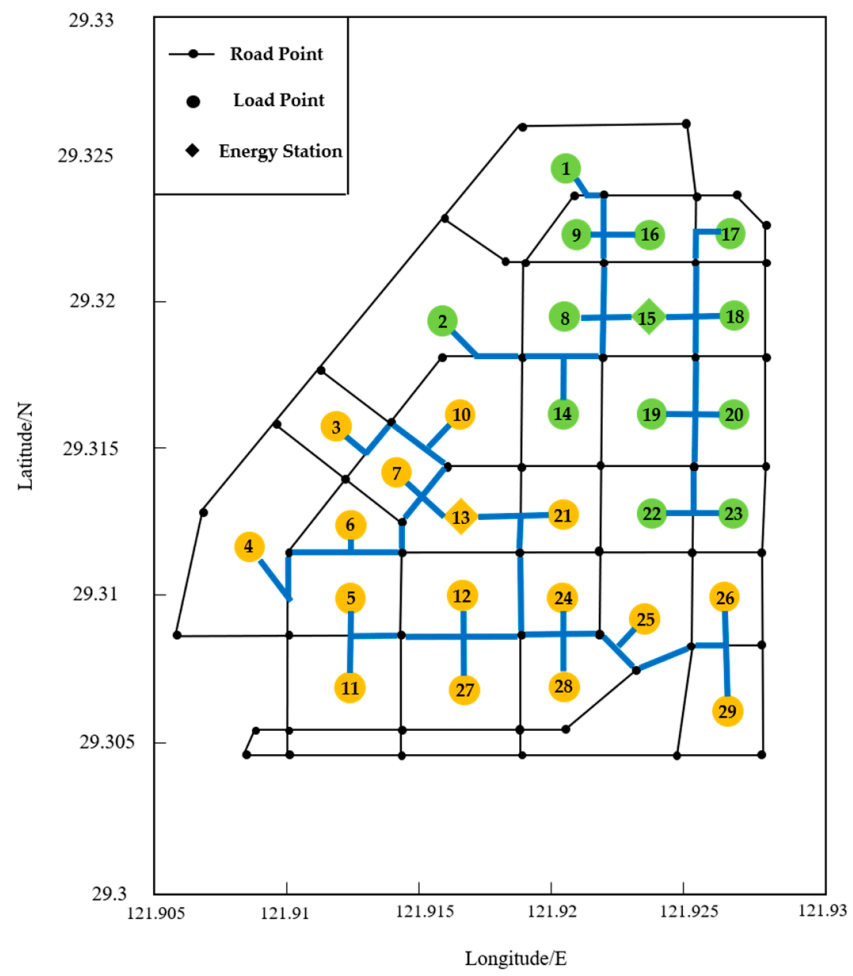

(c) Network planning of Scheme 1

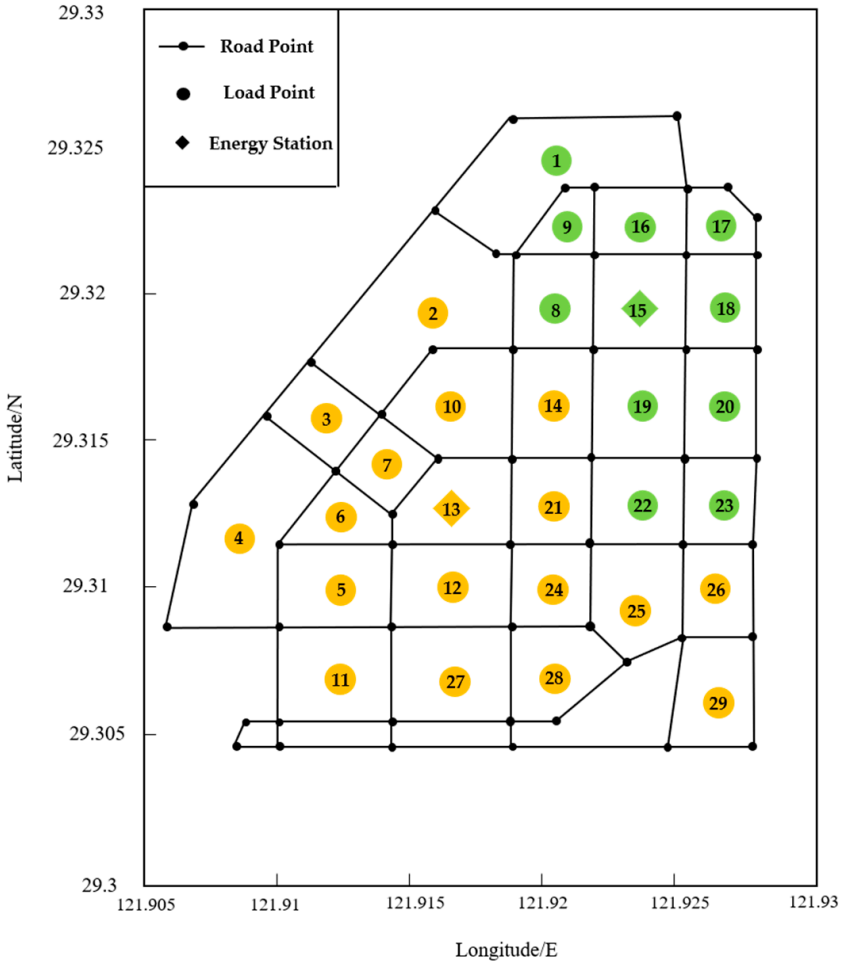

(b) Energy supply area of Scheme 2

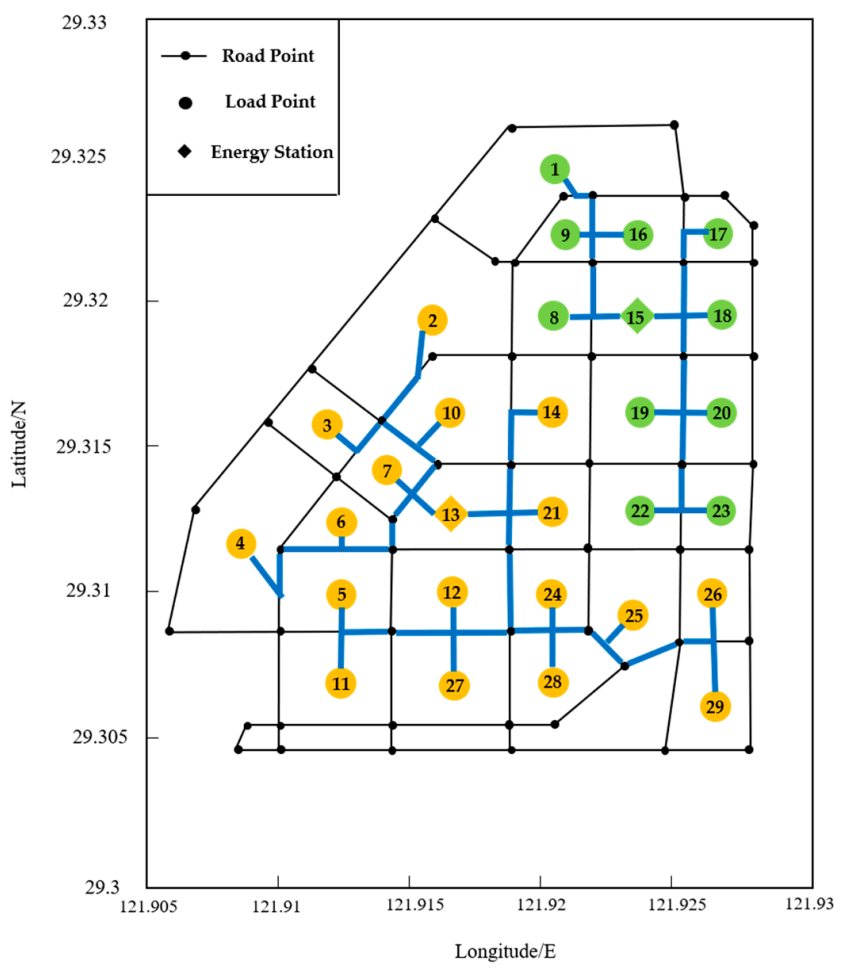

(d) Network planning of Scheme 2

Figure 5. Station and network planning results of Schemes 1 and 2. 


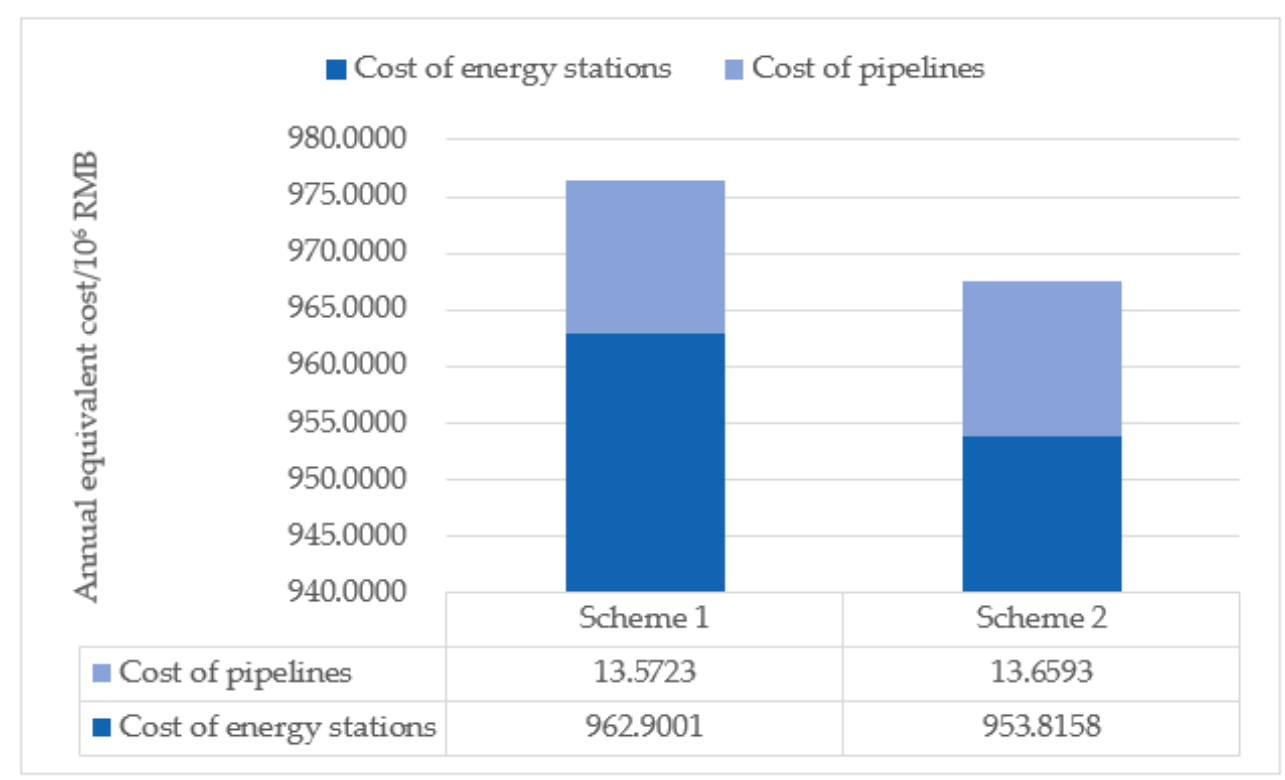

Figure 6. Comparison of two schemes.

According to Figures 5 and 6, it can be observed that the load characteristics are considered, that is, adopting relative-load-distance, so that the load points (load 2 and load 4) are no longer supplied by the nearest energy station (Station 15), but belong to the energy station (Station 13) relatively far away from it. Therefore, the annual conversion cost of the pipe network in Scheme 2 is 87,000 RMB higher than that in Scheme 1, but the decreased cost in the network is significantly less than the increased cost in the energy station. On the contrary, owing to the scale effect, considering the load characteristics of some load points, the overall load characteristics in the energy supply range of each energy station are improved, in which the capacity of Station 13 is increased by $18 \%$, while the capacity of Station 15 is reduced by $26 \%$. Therefore, the total investment cost of the two energy stations is also reduced. In addition, in Figure $5 c, d$, compared with the differences in network distribution between the two schemes, Scheme 2 replaces multiple pipelines in Scheme 1 with public pipelines, which improves the concentration of loads in the region. Considering the annual cost of the energy station and network, compared with Scheme 1, the annual cost of the energy system in Scheme 2 is reduced by 9.1 million yuan. This comparison shows that considering the load characteristics of load points in the division of energy supply range can slightly increase the investment of pipe network, but it can allocate users to appropriate energy stations, effectively reduce the annual cost of energy stations, and is conducive to the economic construction of the energy system.

\subsection{Further Discussion}

In the previous discussion, we take the coefficient $k$ in relative-load-distance as 3 , which proves the feasibility of this optimization method. In this section, we can study the change trend of its impact on the objective function by adjusting the value of the coefficient $k$, so as to provide different station network planning schemes. The table below shows different schemes of different $k$ values.

The change in coefficient $k$ means the change in the number of load points on the boundary of energy supply area. It can be seen from Table 2 that, with the increase in the $k$ value, the number of load points that need to change the ownership on the boundary also increases. The annual cost of the system increases with the increase in the $k$ value, but it is lower than that obtained by dividing the range on the principle of the minimum distance. This is because, although the shortest distance principle ensures the shortest pipeline length and the lowest pipe network cost, from the perspective of the whole system, the system cost is mainly affected by the energy station, and the pipe network cost accounts for only a small part. The shortest distance principle cannot ensure the optimization of 
the overall load characteristics in the energy supply area. This comparison also intuitively proves the effectiveness of relative-load-distance proposed in this study.

Table 2. Results under different $k$ values.

\begin{tabular}{cccc}
\hline Value & $\begin{array}{c}\text { Cost of Energy Stations } \\
\left(\mathbf{1 0}^{\mathbf{6}} \mathbf{R M B}\right)\end{array}$ & $\begin{array}{c}\text { Cost of Pipelines } \\
\left(\mathbf{1 0}^{\mathbf{6}} \mathbf{R M B}\right)\end{array}$ & $\begin{array}{c}\text { Total Cost } \\
\left(\mathbf{1 0 ^ { 6 }} \mathbf{R M B}\right)\end{array}$ \\
\hline$k=3$ & 953.82 & 13.66 & 967.48 \\
$k=4$ & 961.82 & 14.13 & 975.95 \\
$k=5$ & 962.12 & 14.39 & 976.52 \\
Scheme 1 & 962.90 & 13.57 & 976.47 \\
\hline
\end{tabular}

Then, by further analyzing the changes in the cost of energy station and network under different $k$ values, it can be seen that, with the increase in the $k$ value, the cost of the energy station and network increases. However, the growth trend of energy station and network costs gradually slows down, which does not mean that, the more load points to change the ownership, the better. With the increase of load points that need to be changed, the phenomenon of pipeline sharing in the region will be reduced, resulting in a decrease in the concentration of the overall load in the region, which is not conducive to the economy of the energy system.

\section{Conclusions}

This paper proposed a DES optimization model to determine the locations of energy stations, energy supply range, and distributions of networks to minimize the total annual cost of DES. The method mainly included the design process of determining the locations of energy stations with the help of the Voronoi diagram and the optimization process of "relative-load-distance". The feasibility and reliability of the method were verified by a case study. The following conclusions were obtained.

Firstly, based on the Voronoi diagram and improved P-median optimization method, the station location optimization method can not only find the locations of energy stations in the new planning of DES, but also realize the optimal locations of energy stations according to the spatial distribution of load. This method can be applied to planning scenes in which it is difficult to pre-determine the sites to be selected, so as to enhance the concentration of energy stations and pipelines in the region.

Secondly, considering the load characteristics in the division of energy supply range will slightly increase the construction length of the pipeline, but can effectively improve the utilization efficiency of the pipe network, so as to improve the concentration of load in the region, and then improve the economy of the station-network layout scheme.

Finally, the proposed method is verified and compared by vertical and horizontal comparison. Compared with the minimum distance principle, relative-load-distance can correctly deal with the relationship between the cost of the energy station and the cost of the network, and reasonably divide the ownership of users, so as to reduce the total cost by $0.92 \%$. In addition, the sensitivity analysis shows that the coefficient $k$ in relativeload-distance significantly affects the optimal scheme. In the actual planning, the load characteristics in the region should be comprehensively evaluated to reduce the loss.

It should be noted that the accurate locations of the energy stations cannot be determined only by the optimization results of the method proposed in this paper. We also need to consider the geographical conditions, environment, resource distribution, and other factors in the station network planning in DESs. In future research, the scope of optimization should consider different types of customers in each node and the location of the node can also be considered as a variable, which will add more dimensions to the optimization problem.

Author Contributions: Conceptualization, Y.R. and J.Y.; methodology, J.W. and J.Y.; software, F.Q. and J.Y.; validation, H.M., F.Q. and J.Y.; formal analysis, H.M. and J.Y.; investigation, J.W. and J.Y.; 
resources, F.Q. and J.Y.; data curation, Y.R., F.Q. and J.Y.; writing-original draft preparation, H.M., J.W. and J.Y.; writing-review and editing, F.Q., J.W. and J.Y.; supervision, J.W.; project administration, Y.R. All authors have read and agreed to the published version of the manuscript.

Funding: This research was funded by the National Natural Science Foundation of China, grant number 5197081451.

Institutional Review Board Statement: Not applicable.

Informed Consent Statement: Not applicable.

Data Availability Statement: Not applicable.

Acknowledgments: The authors thank the anonymous referees for their valuable comments and suggestions.

Conflicts of Interest: The authors declare no conflict of interest.

\section{Nomenclature}

\begin{tabular}{|c|c|c|c|}
\hline DES & distributed energy system & $C_{o_{i j}}^{P L}$ & $\begin{array}{l}\text { initial investment cost of } \\
\text { pipe network }\end{array}$ \\
\hline CCHP & $\begin{array}{l}\text { combined cooling heating } \\
\text { and power }\end{array}$ & $C_{\Delta Q_{i j}}^{P L}$ & annual cost of heat loss \\
\hline EHV & extra-high voltage & $C_{\alpha_{i j}}^{P L}$ & $\begin{array}{l}\text { depreciation and } \\
\text { maintenance costs }\end{array}$ \\
\hline GA & genetic algorithm & $\chi_{t}^{E S}$ & $\begin{array}{l}\text { standard investment effect } \\
\text { coefficient of energy station }\end{array}$ \\
\hline $\mathrm{PN}$ & pipe network & $\chi_{t}^{P L}$ & $\begin{array}{l}\text { standard investment effect } \\
\text { coefficient of pipelines }\end{array}$ \\
\hline MST & minimum spanning tree & $V^{E S}$ & total capacity of energy stations \\
\hline $\mathrm{N}$ & number of energy stations & $C^{E S}$ & investment cost per unit capacity \\
\hline G & abstract graph of study area & $\mu_{1}^{E S}$ & depreciation cost coefficient \\
\hline V & set of key nodes of G & $\mu_{2}^{E S S}$ & maintenance cost coefficient \\
\hline E & set of edges & $f\left(d_{i}\right)$ & unit length cost of pipe $i$ \\
\hline M & set of load points & $l_{i}$ & length of pipe $i$ \\
\hline $\mathrm{N}$ & set of energy stations & $\Delta Q$ & heat loss \\
\hline$\alpha_{m n}$ & $0 / 1$ variable & $\lambda$ & $\begin{array}{l}\text { thermal conductivity of thermal } \\
\text { insulation materials }\end{array}$ \\
\hline$d_{m n}$ & $\begin{array}{l}\text { the Manhattan distance between } \\
\text { load } m \text { and energy station } n\end{array}$ & $t_{c}$ & temperature difference \\
\hline$Q$ & load value & $\delta_{i}$ & thickness of the pipes \\
\hline$C_{\text {total }}$ & $\begin{array}{l}\text { total annual cost of energy stations } \\
\text { and pipelines }\end{array}$ & $\delta_{t i}$ & thickness of insulation layer \\
\hline$C_{\text {station }}$ & total annual cost of energy stations & $\mathrm{COP}$ & energy efficiency ratio \\
\hline$C_{\text {pipeline }}$ & total annual cost of pipelines & $\alpha$ & depreciation rate \\
\hline$C_{o_{j}}^{E S}$ & $\begin{array}{l}\text { initial total investment cost of energy } \\
\text { station } j\end{array}$ & $\Delta l_{i-1}$ & $\begin{array}{l}\text { distance from the node } i \text { to } \\
\text { energy station } 1\end{array}$ \\
\hline$C_{m_{j}}^{E S}$ & $\begin{array}{l}\text { annual maintenance cost of energy } \\
\text { station } j\end{array}$ & $\Delta l_{i-2}$ & $\begin{array}{l}\text { distance from the node } i \text { to } \\
\text { energy station } 2\end{array}$ \\
\hline$R$ & $\begin{array}{l}\text { energy supply radius of the } \\
\text { planning area }\end{array}$ & $k$ & $\begin{array}{l}\text { coefficient in relative-load- } \\
\text { distance }\end{array}$ \\
\hline
\end{tabular}




\section{Appendix A}

Table A1. Load information in the planning area.

\begin{tabular}{|c|c|c|c|}
\hline Load Node & Longitude/E & Latitude/N & Heating Demand/kW \\
\hline 1 & 121.9215 & 29.32402 & 474.735 \\
\hline 2 & 121.9161 & 29.31935 & 582.972 \\
\hline 3 & 121.9117 & 29.3159 & 399.426 \\
\hline 4 & 121.9092 & 29.31197 & 479.667 \\
\hline 5 & 121.9122 & 29.31005 & 405.952 \\
\hline 6 & 121.9128 & 29.31236 & 403.616 \\
\hline 7 & 121.9141 & 29.31436 & 494.610 \\
\hline 8 & 121.9203 & 29.31971 & 176.612 \\
\hline 9 & 121.9207 & 29.32247 & 381.442 \\
\hline 10 & 121.9166 & 29.31618 & 491.310 \\
\hline 11 & 121.9123 & 29.30704 & 540.849 \\
\hline 12 & 121.9165 & 29.31005 & 656.094 \\
\hline 13 & 121.9165 & 29.31292 & 930.486 \\
\hline 14 & 121.9202 & 29.31625 & 157.635 \\
\hline 15 & 121.9234 & 29.3197 & 553.197 \\
\hline 16 & 121.9234 & 29.32245 & 469.359 \\
\hline 17 & 121.9263 & 29.32246 & 211.545 \\
\hline 18 & 121.9263 & 29.31971 & 393.048 \\
\hline 19 & 121.9233 & 29.31626 & 524.867 \\
\hline 20 & 121.9263 & 29.31626 & 129.014 \\
\hline 21 & 121.9202 & 29.31293 & 107.970 \\
\hline 22 & 121.9233 & 29.31293 & 409.178 \\
\hline 23 & 121.9262 & 29.31292 & 444.960 \\
\hline 24 & 121.9204 & 29.30983 & 404.357 \\
\hline 25 & 121.9232 & 29.30944 & 369.799 \\
\hline 26 & 121.9262 & 29.30983 & 437.989 \\
\hline 27 & 121.9165 & 29.3071 & 425.085 \\
\hline 28 & 121.9204 & 29.3071 & 551.713 \\
\hline 29 & 121.9261 & 29.30643 & 1024.653 \\
\hline
\end{tabular}

\section{References}

1. Bongaarts, J. Intergovernmental Panel on Climate Change Special Report on Global Warming of $1.5^{\circ} \mathrm{C}$; Population and Development Review 2018; IPCC: Geneva, Switzerland, 2019. [CrossRef]

2. Hua, H.; Qin, Y.; Hao, C.; Cao, J. Optimal energy management strategies for energy internet via deep reinforcement learning approach. Appl. Energy 2019, 239, 598-609. [CrossRef]

3. Colak, I.; Sagiroglu, S.; Fulli, G.; Yesilbudak, M.; Covrig, C.F. A survey on the critical issues in smart grid technologies. Renew. Sustain. Energy Rev. 2016, 54, 396-405. [CrossRef]

4. Wang, J.; Han, Z.; Guan, Z. Hybrid solar-assisted combined cooling, heating, and power systems: A review-ScienceDirect. Renew. Sustain. Energy Rev. 2020, 133, 110256. [CrossRef]

5. Fransson, V.; Bagge, H.; Johansson, D. Impact of variations in residential use of household electricity on the energy and power demand for space heating —Variations from measurements in 1000 apartments. Appl. Energy 2019, 254, 113559. [CrossRef]

6. Guan, L.; Chen, P.; Tang, Z.; Chen, X.; Jiang, Z. Integrated Energy Station Design Considering Cold and Heat Storage. Power Syst. Technol. 2016, 40, 2934-2941. [CrossRef]

7. Sameti, M.; Haghighat, F. Optimization approaches in district heating and cooling thermal network. Energy Build. 2017, 140, 121-130. [CrossRef]

8. Vesterlund, M.; Toffolo, A. Design optimization of a district heating network expansion, a case study for the town of kiruna. Appl. Sci. 2017, 7, 488. [CrossRef]

9. Zeng, J.; Han, J.; Zhang, G. Diameter optimization of district heating and cooling piping network based on hourly load. Appl. Therm. Eng. 2016, 107, 750-757. [CrossRef]

10. Chan, A.; Hanby, V.I.; Chow, T.T. Optimization of distribution piping network in district cooling system using genetic algorithm with local search. Energy Convers. Manag. 2007, 48, 2622-2629. [CrossRef]

11. Chen, Y.; Zhu, J. A graph theory-based method for regional integrated energy network planning: A case study of a China-U.S. low-carbon demonstration city. Energies 2019, 12, 4491. [CrossRef] 
12. Mosbah, M.; Arif, S.; Mohammedi, R.D.; Hellal, A. Optimum dynamic distribution network reconfiguration using minimum spanning tree algorithm. In Proceedings of the 2017 5th International Conference on Electrical Engineering-Boumerdes (ICEE-B), Boumerdes, Algeria, 29-31 October 2017. [CrossRef]

13. Dobersek, D.; Goricanec, D. Optimisation of tree path pipe network with nonlinear optimisation method. Appl. Therm. Eng. 2008, 29, 1584-1591. [CrossRef]

14. Yan, R.; Wang, J.; Zhu, S.; Liu, Y.; Cheng, Y.; Ma, Z. Novel planning methodology for energy stations and networks in regional integrated energy systems. Energ. Convers. Manag. 2020, 205, 112441. [CrossRef]

15. Wang, Y.; Wang, J.; Gao, M.; Zhang, D.; Liu, Y.; Tan, Z.; Zhu, J. Cost-based siting and sizing of energy stations and pipeline networks in integrated energy system. Energy Convers. Manag. 2021, 235, 113958. [CrossRef]

16. Chen, J.; Huang, Y.; Lu, B. Research on "Stations-Pipelines" Layout and Optimization of Regional Energy Internet. Proc. CSEE 2018, 38, 675-684. [CrossRef]

17. Wang, J.; Yang, Y.; Sui, J.; Jin, H. Multi-objective energy planning for regional natural gas distributed energy: A case study. J. Nat. Gas Sci. Eng. 2016, 28, 418-433. [CrossRef]

18. Wang, Z.; Liu, Q.; Ruan, Y.; Wang, H. Research and Application of Optimal Layout Method for Station Network Layout in Regional Energy Planning. J. Eng. Therm. Energy Power 2019, 34, 25-30. [CrossRef]

19. Xu, Y.; Zhang, J. Regional integrated energy site layout optimization based on improved artificial immune algorithm. Energies 2020, 13, 4381. [CrossRef]

20. Chen, D.; Abbas, M.Z.; Li, Y.; Hu, X.; Liu, Y. Optimal centralized integrated energy station site approach based on energy transmission loss analysis. Int. J. Energy Res. 2021, 45, 894-907. [CrossRef]

21. Wang, X.; Sun, J.; Yi, W. P-Median Model Based Optimization of Energy Supply Station Sites and Pipelines Layout for Integrated Energy System. In Proceedings of the 2018 2nd IEEE Conference on Energy Internet and Energy System Integration (EI2) IEEE, Beijing, China, 20-22 October 2018. [CrossRef]

22. Norde, H. The degree and cost adjusted folk solution for minimum cost spanning tree games. Games Econ. Behav. 2019, 113, 734-742. [CrossRef]

23. Prim, R.C. Shortest connection networks and some generalizations. Bell Syst. Tech. J. 1957, 36, 1389-1401. [CrossRef]

24. Kruskal, J.B. On the shortest spanning subtree of a graph and the traveling salesman problem. Proc. Am. Math. Soc. 1956, 7, 48-50. [CrossRef] 